\title{
Acute effects of non-homogenised and homogenised vegetables added to rice-based meals on postprandial glycaemic responses and in vitro carbohydrate digestion
}

\author{
Ruixin Zhu ${ }^{1}$, Manman $\mathrm{Liu}^{2}$, Yue $\mathrm{Han}^{3}$, Linlin Wang ${ }^{1}$, Ting $\mathrm{Ye}^{1}$, Jiacan $\mathrm{Lu}^{3}$ and Zhihong Fan ${ }^{1 *}$ \\ ${ }^{1}$ Beijing Advanced Innovation Centre for Food Nutrition and Human Health, College of Food Science and Nutritional \\ Engineering, China Agricultural University, Beijing 100083, People's Republic of China \\ ${ }^{2}$ Department of Food Science and Engineering, College of Biological Science and Technology, Beijing Forestry University, \\ Beijing 100083, People's Republic of China \\ ${ }^{3}$ College of Biological Sciences, China Agricultural University, Beijing 100094, People's Republic of China
}

(Submitted 18 February 2018 - Final revision received 2 August 2018 - Accepted 6 August 2018)

\begin{abstract}
The addition of vegetable to carbohydrate-based meals was shown to contribute to glycaemic management. The aim of this study was to investigate the impact of homogenisation on vegetables added to rice meals in terms of acute glycaemic responses (GR). In a randomised crossover trial, sixteen healthy volunteers completed thirteen test sessions, which included two sessions for glucose control, two for rice and nine for different vegetable-rice mixed meals: cooked pak choi and cooked rice $(\mathrm{CP}+\mathrm{R})$; cooked cauliflower and cooked rice $(\mathrm{CC}+\mathrm{R})$; cooked eggplant and cooked rice $(\mathrm{CE}+\mathrm{R})$; and their homogenised counterparts, both raw or cooked. Postprandial GR tests, in vitro carbohydrate digestion and chemical analyses were carried out for each test meal. Compared with pure rice, $\mathrm{CE}+\mathrm{R}, \mathrm{CP}+\mathrm{R}$ and $\mathrm{CC}+\mathrm{R}$ meals achieved significantly lower glycaemic indexes (GI) of 67,71 and 73 , whereas their homogenised counterparts failed to show significant difference with rice. The hydrolysis indexes (HI) of $\mathrm{CE}+\mathrm{R}, \mathrm{CP}+\mathrm{R}$ and $\mathrm{CC}+\mathrm{R}$ were $69 \cdot 6,83.8$ and $80 \cdot 6 \%$ of the HI of the rice control. CE had the greatest effect on lowering the GI, the incremental area under the blood glucose curve from 0 to 120 min, the peak glucose value, the maximum amplitude of glucose excursion in 0-120 $\mathrm{min}\left(\mathrm{MAGE}_{0-120}\right)$, the $\mathrm{HI}$ and rapid available starch. Both in vitro and in vivo tests demonstrated that incorporating non-homogenised cooked vegetables into a rice meal could slow the carbohydrate digestion and improve postprandial GR. Texture properties of vegetable may play an important role in underlying glycaemic control mechanisms.
\end{abstract}

Key words: Glycaemic responses: Homogenised vegetables: Cooked vegetables: In vitro carbohydrate digestion

Rice is the most commonly consumed staple food and the major dietary source of carbohydrates in many Asian countries. However, refined white rice has been classified as a high glycaemic index (GI) food in previous studies ${ }^{(1,2)}$, and daily consumption of a high-GI rice-based diet may induce hyperglycaemia after meals, even in healthy people ${ }^{(3)}$. A sustained elevated postprandial blood glucose level is strongly associated with an elevated risk of type 2 diabetes mellitus $(\mathrm{T} 2 \mathrm{DM})^{(4)}$. It is estimated that the number of diabetes patients will reach 123.0 and 201.8 million in 2035 in South East Asia and the West Pacific region, respectively ${ }^{(5)}$. Dietary interventions that can attenuate postprandial glycaemic responses (GR) have been proven beneficial for T2DM prevention $^{(6)}$, and these interventions are encouraged by professional bodies ${ }^{(7)}$.
As a staple food, rice is usually co-consumed with other dishes, such as vegetables, meat, fish and soya foods in East Asia and South Asia. The addition of vegetables deserves to be highlighted as vegetables are high nutrient density food, rich in dietary fibre and phytochemicals such as polyphenols and carotenoids. Accumulating epidemiological evidence and intervention trials support that sufficient vegetable intake, especially the intake of green leafy vegetables ${ }^{(8-10)}$ and cruciferous vegetables ${ }^{(11)}$, are associated with reduced risk of T2DM.

A number of research reports have shown that, compared with the GR of pure rice, the GR of rice-based mixed meals could be reduced by the incorporation of a variety of vegetables, although the amount of total available carbohydrate of the vegetable-rice mixed meal was higher than that of the pure rice meal ${ }^{(12-14)}$. Eating vegetable dishes before taking

Abbreviations: CC, cooked cauliflower; CE, cooked eggplant; CP, cooked pak choi; GI, glycaemic index; GR, glycaemic response; iAUC, incremental AUC; RS, resistant starch

* Corresponding author: Z. Fan, fax +8610 62737717, email daisyfan@cau.edu.cn 
carbohydrate-based food improved postprandial glucose excursions in day-long glycaemic tests and lowered the HbA1c after year-long intervention in diabetes patients ${ }^{(15)}$. Leafy vegetable juices were also reported as a possible contributor to supressing postprandial GR in preload studies in both healthy adults $^{(16)}$ and rats ${ }^{(17)}$ when consumed before ingestion of highGI foods.

The possible mechanisms of mitigating GR by adding vegetable to a high-GI carbohydrate diet can be explained as follows: (1) dietary fibre can delay gastric emptying ${ }^{(18,19)}$; (2) soluble fibre may lower the postprandial $\mathrm{GR}^{(20)}$ and (3) phytochemicals, including polyphenols, may inhibit intestinal $\alpha$-glucosidase activity and thus could slow the digestion rate of food carbohydrates ${ }^{(21)}$. However, the gastric emptying process may be affected by food texture factors, and the type of dietary fibre might make a difference in the GR-suppressing effect, as insoluble fibre has been shown to be ineffective in lowering food GI or $\mathrm{GR}^{(22)}$.

In the previous studies, the vegetable samples were prepared as salad $^{(15)}$, boiled ${ }^{(23)}$, microwaved $^{(21)}$ or juiced ${ }^{(16,21)}$. However, it has not yet been reported whether the physical structures of vegetable samples or their cooking status could significantly contribute to their glycaemic suppression capacity.

Therefore, we assumed that texture/physical properties of vegetables would have a crucial effect on postprandial GR. To examine this hypothesis, three kinds of commonly consumed vegetables including Pak choi, cauliflower and eggplant were chosen as samples. The vegetables were (1) cooked, (2) cooked and homogenised or (3) homogenised raw, before being incorporated into vegetable-rice mixed test meals. The acute GR of the test meals, as well as the in vitro carbohydrate digestion indicators of the above-mentioned vegetable-rice mixed meals, was measured.

\section{Methods}

\section{Pre-treatment of test foods}

Pak choi (Brassica rapa var. chinensis), cauliflower (Brassica oleracea L.) and eggplant (Solanum melongena L.) were brought from the local market. Pak choi leaves were peeled from the roots and were washed in tap water for $4 \mathrm{~min}$. Floret bouquets were cut from the cauliflower heads and were washed in tap water for $4 \mathrm{~min}$. Eggplant was washed in tap water for $2 \mathrm{~min}$ and cut into 4-mm slices.

\section{Preparation of test meals}

After the pre-treatment, a preliminary sensory test was conducted to evaluate the acceptability of multiple vegetable samples cooked with minimal amount of oil (2.5/300 g fresh vegetable). The steamed eggplant, boiled cauliflower and boiled pak choi were chosen for their satisfactory acceptability. Subjects were offered nine different white-rice-based meals, as shown in Fig. 1. Glucose $\left(50 \mathrm{~g}\right.$ of Glucolin ${ }^{\circledR}$ (The British Dispensary (L.P.) Co. Ltd) dissolved in $250 \mathrm{ml}$ of water) and rice containing $50 \mathrm{~g}$ of available carbohydrates were prepared as dual reference foods. The tested rice meals were as follows: (1) cooked rice (R) (2) cooked rice
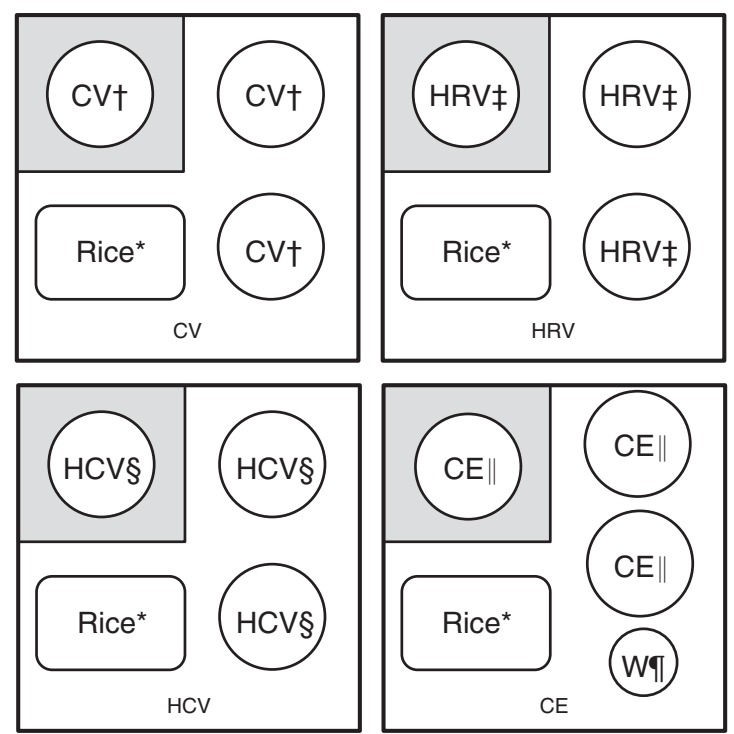

Fig. 1. Composition of vegetable-rice mixed meals; the size of each meal is $569.1 \mathrm{~g}$ (water used for cooking or balancing the weight included) or $370 \mathrm{~g}$ (water used for cooking or balancing the weight not included); participants were given one serving of a vegetable sample first (shown in grey squares), and they were instructed to consume two additional servings of vegetable samples with cooked rice. $\mathrm{CV}$, cooked vegetable; $\mathrm{HRV}$, homogenised raw vegetable; $\mathrm{HCV}$, homogenised cooked vegetable; CE, cooked eggplant; W, water. * Cooked rice (raw materials: $66.1 \mathrm{~g}$ of raw rice and $99.0 \mathrm{~g}$ of water). $\dagger$ One serving of cooked vegetable, except CE. $\ddagger$ One serving of HRV. $\S$ One serving of HCV. ॥ One serving of CE. I $100 \mathrm{~g}$ of $\mathrm{W}$.

with cooked vegetables, including cooked pak choi (CP), cooked cauliflower (CC) and cooked eggplant (CE); (3) cooked rice with homogenised raw vegetables, including homogenised raw pak choi (HRP), homogenised raw cauliflower (HRC) and homogenised raw eggplant (HRE); and (4) cooked rice with homogenised cooked vegetables, including homogenised cooked pak choi (HCP), homogenised cooked cauliflower (HCC) and homogenised cooked eggplant (HCE). The sensory test showed that homogenised raw vegetables had lower scores compared with their non-homogenised counterparts, but they were accepted by the subjects.

The test meals were combinations of cooked rice and $300 \mathrm{~g}$ of vegetable samples (Table 1). Long-grain fragrant white rice was used and steamed in a single-portion plastic container at $1000 \mathrm{~W}$ for $40 \mathrm{~min}$. Each rice portion $(66 \cdot 1 \mathrm{~g}$ of raw rice) was cooked individually using $99.0 \mathrm{~g}$ of water. The vegetables were prepared as follows. (1) Cooked vegetables were prepared by either boiling or steaming, including steamed eggplant, boiled pak choi and boiled cauliflower. For boiling, well-cut pak choi/ cauliflower was placed in a saucepan with $300 \mathrm{~g}$ of boiling water, $1.5 \mathrm{~g}$ of salt and $2.5 \mathrm{~g}$ of sesame oil. Vegetables were cooked for exactly $2 \mathrm{~min}$ at a power of $1000 \mathrm{~W}$ with an induction cooker. The boiled vegetables were given to the subjects along with the remaining water (about $100 \mathrm{~g}$ ). For steaming, sliced eggplant was tiled on the removable bottom of an electric steamer (Viva Collection; Philips) and steamed for exactly $10 \mathrm{~min}$. The steamed eggplant was immediately placed on a plate and sprinkled with $2.5 \mathrm{~g}$ of oil and $1.5 \mathrm{~g}$ of salt. To balance the size of the meals, half a glass of water $(100 \mathrm{~g})$ was offered, when participants consumed the steamed eggplant. 
(2) Homogenised raw vegetables were prepared by putting the raw vegetables in a high-performance blender (WBL1031S; Midea) along with $100 \mathrm{~g}$ of water, $2.5 \mathrm{~g}$ of oil and $1.5 \mathrm{~g}$ of salt and was mashed for exactly $30 \mathrm{~s}$ at the top speed (25000 rpm). (3) Homogenised cooked vegetables were cooked before mashing. The prepared vegetable samples were equally divided into three servings before the blood glucose tests, each serving containing $100 \mathrm{~g}$ of raw vegetable (Fig. 1).

\section{Chemical analysis of test meals}

The nutrient composition and phenolic compound content of vegetables and rice were analysed as follows. Total starch content was examined using a Megazyme assay kits (Megazyme International Ireland Limited) according to AOAC 996.11. Reducing sugar content was assayed using Lane-Eynon general volumetric method according to AOAC 945.66 and AOAC 923.09. Available carbohydrate content was calculated by the sum of total starch content and reducing sugar content ${ }^{(24)}$. Protein content was estimated using the method of Kjeldahl according to ISO 1871:2009. Total fat content was assessed by ISO 6492:1999. Total dietary fibre, soluble dietary fibre and insoluble dietary fibre contents were examined using an enzymatic-gravimetric method according to AOAC 991.43. Water content was determined according to ISO 1026:1982. Total energy was calculated as described by EU Council Directive $1169 / 2011^{(25)}$. Total polyphenol content was determined with Folin-Ciocalteu reagents according to the method of Singleton et $a{ }^{(26)}$, and expressed as $\mathrm{mg}$ gallic acid equivalent/100 $\mathrm{g}$ fresh weight (FW) basis. Total flavonoid content was determined with aluminium trichloride reagents, and expressed as mg rutin equivalent/100 g FW basis ${ }^{(27)}$. Total tannin content was determined using acidified vanillin ${ }^{(28)}$ and expressed as mg catechin equivalent/100 g FW basis.

\section{Glycaemic response testing subjects}

Healthy young women aged between 18 and 24 years with BMI between 20 and $24.9 \mathrm{~kg} / \mathrm{m}^{2}$ were recruited through advertisements on the university website. Questionnaires were given to subjects to ensure that all individuals met the following criteria: not pregnant; not in their menstrual period; non-smoker; nondrinker; free from food allergies; stable weight for the past 3 months; regularly eating three meals, not skipping breakfast; not on diet to gain or to lose weight; not on prescription medication in the past 3 months; no metabolic disease or familial history of diabetes; and no impaired glucose tolerance or impaired fasting glycaemia. The sample size was calculated using PASS 13 Power Analysis and Sample Size software (NCSS). It revealed that the test would have $80 \%$ power to examine a difference $(P<0.05)$ with sixteen subjects in incremental AUC (iAUC) of $20 \cdot 0 \mathrm{mmol} / 1 \times 2 \mathrm{~h}$. Potential female subjects who met these initial criteria were invited to the laboratory to finish additional exams, including an oral glucose tolerance test and a rice control test, which were tested twice for each subject. All eligible individuals signed informed consent forms. This study was conducted according to the Declaration of Helsinki and carried out at the College of Food Science and 
Nutritional Engineering, China Agricultural University. The study protocol was approved by the Ethics Committee of China Agricultural University (ethics no. 2016011) and all the subjects signed written informed consent. There was no uncomfortable occasion during the test sessions.

\section{Glycaemic response testing procedures}

The study protocol used was in line with the standard procedures recommended by the FAO and the WHO. This study was conducted using a randomised crossover design in which subjects ate test meals in a randomised order on thirteen separate mornings, including nine times for different vegetablerice mixed meals, twice for glucose control and twice for rice control, with a wash-out period of 1 week between each test session. In all, $1 \mathrm{~d}(24 \mathrm{~h})$ before each trial day, the participants were instructed to refrain from excessive eating, alcoholic beverages, staying up late and strenuous exercise. The subjects arrived at the laboratory at 08.00 hours, and their baseline blood glucose level was tested after a 10-min rest. The test meals were given to the subjects at 08.15 hours. At the beginning of each test meal, participants were given one serving (equivalent to $100 \mathrm{~g}$ of vegetable material) of a vegetable sample first (preload), and they were instructed to consume the preload in $10 \mathrm{~min}$. Then they were given two additional servings of vegetable samples with cooked rice (co-ingestion) and were asked to finish the meal within $20 \mathrm{~min}$. The ingestion time was recorded and the eating rate was calculated as the total energy of a meal $(\mathrm{kJ})$ consumed per unit time (min). The finger-prick blood samples were taken at 30, 45, 60, 90, 120, 150, 180, 210 and $240 \mathrm{~min}$ following the start of the test meals (Fig. 2). The second drop of blood was used for testing to avoid possible plasma dilution. Subjects were served $200 \mathrm{ml}$ of water between 90 and $120 \mathrm{~min}$. Subjects were provided with books, magazines and Wi-Fi and were advised to remain seated during the test session. They were not permitted to eat foods that were not related to the experiment or to discuss the test meals. To assess the reliability of the study procedure, the glucose reference and the rice samples were tested twice. Plasma blood glucose was analysed using a ONE TOUCH UltraEasy glucometer (Johnson \& Johnson), which used the glucose oxidase method.

\section{In vitro determination of starch digestibility}

In vitro digestion of starch from the test meals was assessed using a modified Englyst method ${ }^{(29,30)}$. The enzyme solution was prepared by adding $0.45 \mathrm{~g}$ of porcine pancreatic $\alpha$-amylase (150 U/mg; EC 3.2.1.1; A3176; Sigma) into $16 \mathrm{ml}$ of water at $37^{\circ} \mathrm{C}$. The mixture was stirred for $10 \mathrm{~min}$ and centrifuged for $10 \mathrm{~min}$. Then, $2 \mathrm{ml}$ of amyloglucosidase $(3000 \mathrm{U} / \mathrm{ml}, E C$
3.2.1.3.; Megazyme) was quickly added to $10 \mathrm{ml}$ of the enzyme supernatant. The pre-treatment and cooking procedures of the white rice and vegetables were the same as those used in blood glucose testing. After treatment, a portion of cooked rice and three servings of vegetable samples were mashed together evenly with a Midea high-performance blender at the lowest speed $(3000 \mathrm{rpm})$ for $30 \mathrm{~s}$ to simulate chewing. Approximately $500 \mathrm{mg}$ of mash was mixed into $4 \mathrm{ml}$ of sodium acetate buffer $(0 \cdot 1 \mathrm{~mol} / \mathrm{l}, \mathrm{pH} 5 \cdot 1)$. The mixture was incubated in a shaking water bath $\left(37^{\circ} \mathrm{C}, 200\right.$ strokes $\left./ \mathrm{min}\right)$ as soon as $1 \mathrm{ml}$ of the fresh enzyme solution was added. The aliquot $(200 \mu \mathrm{l})$ from this phase was mixed with $95 \%$ ethanol at 0, 2, 5, 10, 20, 60 and $120 \mathrm{~min}$ to stop enzyme activity. Released glucose was analysed using a GAGO20 Glucose Assay Kit (Sigma).

\section{Statistical analysis}

The total AUC of postprandial GR (iAUC), the incremental value of peak blood glucose and the maximum amplitudes of glucose excursion in $240 \mathrm{~min}\left(\mathrm{MAGE}_{240}\right)^{(31)}$ were calculated. The iAUC of postprandial GR was determined using the trapezoidal method ${ }^{(32)}$, ignoring the area beneath the fasting level. The rapidly digestible starch (RDS), slowly digestible starch (SDS), resistant starch (RS) and hydrolysis index $(\mathrm{HI})^{(29)}$ were also calculated. The GI was defined as the $\mathrm{iAUC}_{0-120}$ of the blood glucose response curve of $50 \mathrm{~g}$ of the glycaemic carbohydrate portion expressed as a percentage of the response to the same amount of carbohydrate from the glucose as a reference. The GI was calculated from the two iAUC $_{0-120}$ areas. The data were analysed using SPSS 21.0 software (SPSS Inc.). The Kolmogorov-Smirnov test found that most data were normally distributed, and natural logarithmic transformation was used where data failed to present normality. Then data analysis was performed by one-factor repeated-measures ANOVA, with post hoc analysis when applicable. $P$ values were adjusted for multiple comparisons using the Bonferroni correction. Statistical significance was considered to be $P<0.05$. The correlation of data was determined using Pearson's correlation analysis, $P<0.05$. Data were presented as mean values (standard deviations) or mean values (standard errors) where appropriate.

\section{Results}

\section{Chemical composition of test meals}

The nutrient composition of raw vegetables is shown in Table 1, and phenolic compound content of vegetable meals (rice not included) is presented in Table 2. CE had the highest total polyphenol and total flavonoid contents. There was no difference between cooked vegetables and homogenised raw vegetables in terms of total polyphenol and total flavonoid contents.

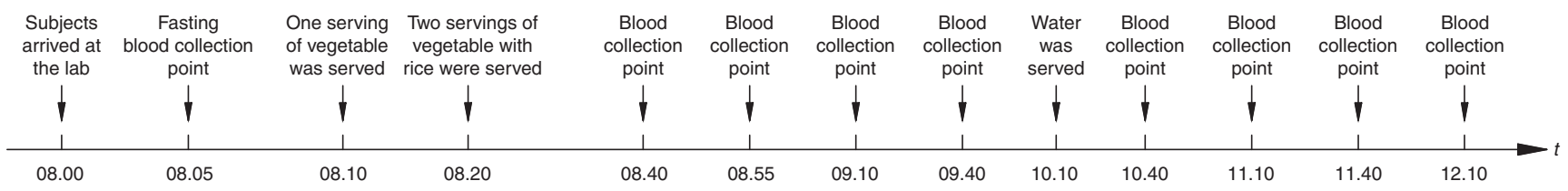

Fig. 2. Glycaemic response test flow. 
Table 2. Phenolic compound content of test vegetables (per serving, $100 \mathrm{~g}$ )

(Mean values and standard deviations)

\begin{tabular}{|c|c|c|c|c|c|c|}
\hline \multirow[b]{2}{*}{ Sample } & \multicolumn{2}{|c|}{ Total polyphenol (mg GAE)* } & \multicolumn{2}{|c|}{ Total flavonoid (mg RUE)† } & \multicolumn{2}{|c|}{ Total tannin (mg CAE) $\ddagger$} \\
\hline & Mean & SD & Mean & SD & Mean & SD \\
\hline $\mathrm{CP}$ & $6381 \cdot 0^{\mathrm{b}}$ & $146 \cdot 6$ & $1034 \cdot 5^{d}$ & $67 \cdot 1$ & $722 \cdot 8^{c}$ & 11.6 \\
\hline HRP & $6115 \cdot 2^{b}$ & $72 \cdot 8$ & $1335 \cdot 3^{\mathrm{b}, \mathrm{c}, \mathrm{d}}$ & $166 \cdot 2$ & $722 \cdot 1^{\mathrm{c}}$ & 14.0 \\
\hline $\mathrm{HCP}$ & $5385 \cdot 5^{c}$ & 88.7 & $1335 \cdot 3^{\mathrm{b}, \mathrm{c}, \mathrm{d}}$ & $166 \cdot 2$ & $549 \cdot 7^{d}$ & 8.5 \\
\hline $\mathrm{CC}$ & $6698 \cdot 0^{a, b}$ & 75.5 & $1736 \cdot 4^{\mathrm{b}}$ & $224 \cdot 7$ & $742 \cdot 6^{c}$ & $15 \cdot 4$ \\
\hline HRC & $6516 \cdot 4^{\mathrm{b}}$ & 199.5 & $1732 \cdot 0^{\mathrm{b}}$ & 108.4 & $762 \cdot 1^{c}$ & $15 \cdot 6$ \\
\hline $\mathrm{HCC}$ & $4691.9^{d}$ & 60.9 & $1536 \cdot 7^{\mathrm{b}, \mathrm{c}}$ & $157 \cdot 3$ & $493.5^{e}$ & $11 \cdot 2$ \\
\hline $\mathrm{CE}$ & $6978 \cdot 2^{a}$ & $145 \cdot 5$ & $2491 \cdot 3^{a}$ & $242 \cdot 6$ & $858 \cdot 2^{b}$ & $24 \cdot 1$ \\
\hline HRE & $6913 \cdot 7^{\mathrm{a}}$ & 81.4 & $2207 \cdot 4^{a}$ & $175 \cdot 0$ & $939.8^{a}$ & $19 \cdot 7$ \\
\hline HCE & $5254 \cdot 8^{c}$ & $132 \cdot 6$ & $1133 \cdot 9^{c, d}$ & 66.4 & $584 \cdot 3^{d}$ & $20 \cdot 8$ \\
\hline
\end{tabular}

GAE, gallic acid equivalent; RUE, rutin equivalent; CAE, catechin equivalent; CP, cooked pak choi; HRP, homogenised raw pak choi; HCP, homogenised cooked pak choi; CC, cooked cauliflower; HRC, homogenised raw cauliflower; HCC, homogenised cooked cauliflower; CE, cooked eggplant; HRE, homogenised raw eggplant; HCE, homogenised cooked eggplant.

a,b,c,d,e Mean values within a column with unlike superscript letters were significantly different $(P<0.05)$.

* Total polyphenol content is expressed as $\mathrm{mg}$ GAE/ $100 \mathrm{~g}$ fresh weight.

$\dagger$ Total flavonoid content is expressed as $\mathrm{mg}$ RUE/ $100 \mathrm{~g}$ fresh weight.

$\ddagger$ Total tannin content is expressed as $\mathrm{mg} C A E / 100 \mathrm{~g}$ fresh weight.

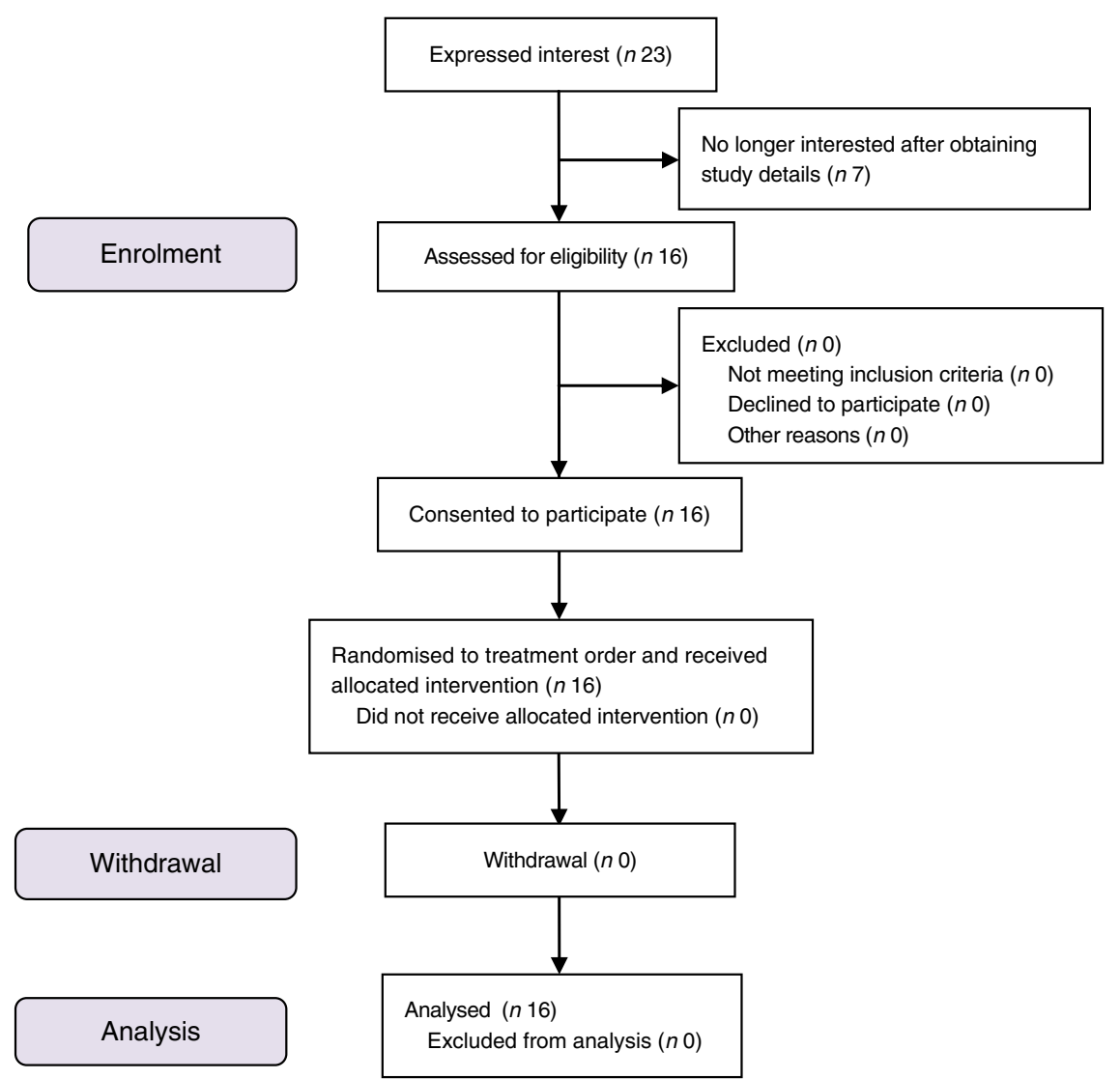

Fig. 3. Consolidated Standards of Reporting Trials (CONSORT) flow diagram of the study subjects.

\section{Subject enrolment}

The study subject flow of both reference food tests and vegetablerice mixed meals is shown in a Consolidated Standards of Reporting Trials (CONSORT) flow diagram (Fig. 3). A total of sixteen subjects completed all the test meals and reference food, and each subject was a control of themselves. All data were included in analyses.

\section{Subject characteristics}

Subject baseline characteristics are shown in Table 3.

\section{Blood glucose}

The postprandial GR for all test meals are shown in Fig. 4. In all, sixteen subject had a mean fasting blood glucose concentration 
Table 3. Subject baseline characteristics (Mean values and standard deviations, $n$ 16)

\begin{tabular}{lcc}
\hline Characteristics & Mean & SD \\
\hline Number of participants $(n)$ & 16 & \\
Age (years) & $22 \cdot 8$ & $1 \cdot 2$ \\
Body height $(\mathrm{cm})$ & $161 \cdot 1$ & $3 \cdot 9$ \\
Body weight $(\mathrm{kg})$ & $54 \cdot 2$ & $4 \cdot 2$ \\
BMl $\left(\mathrm{kg} / \mathrm{m}^{2}\right)$ & $21 \cdot 0$ & $1 \cdot 6$ \\
Fat mass $(\%)$ & $24 \cdot 8$ & $2 \cdot 8$ \\
BMR $(\mathrm{kJ} / \mathrm{d})$ & 5017 & 226 \\
\hline
\end{tabular}

of $4.8(\mathrm{SE} 0.4) \mathrm{mmol} / \mathrm{l}$, and there was no difference among treatments in terms of fasting blood glucose concentrations. All rice-based meals attained peak glucose values at $45 \mathrm{~min}$. Compared with the rice control $(7 \cdot 2(\mathrm{SE} 0 \cdot 2) \mathrm{mmol} / \mathrm{l})$, the $\mathrm{CE}+\mathrm{R}$ meal had significantly lower glucose levels at both 30 and $45 \mathrm{~min}(6.5$ (sE 0.2$) \mathrm{mmol} / \mathrm{l}, \quad P=0.008 ; 6.7$ (SE 0.2) $\mathrm{mmol} / \mathrm{l}$, $P=0 \cdot 005$, respectively), whereas the $\mathrm{CP}+\mathrm{R}$ and $\mathrm{CC}+\mathrm{R}$ meals had significantly lower blood glucose values at $60 \mathrm{~min}(6.4$ (se 0.3 ) $\mathrm{mmol} / 1, P=0.033 ; 6.4$ (sE 0.3 ) $\mathrm{mmol} / 1, P=0.037$, respectively). The $\mathrm{CP}+\mathrm{R}$ and $\mathrm{CC}+\mathrm{R}$ meals better maintained glucose concentrations than the rice control did during 150-240 min.

All three kinds of non-homogenised vegetable-rice mixed meals had significantly reduced GI values compared with the rice control. Compared with ingestion of rice control, ingestion of the $\mathrm{CE}+\mathrm{R}$ meal significantly reduced the peak, $\mathrm{iAUC}_{0-120}$ and MAGE $_{240}$ values, which resulted in a medium GI value of 67 without causing a significant reduction in the iAUC ${ }_{120-240}$ value (Table 4). The $\mathrm{iAUC}_{0-120}$ values of both $\mathrm{CE}+\mathrm{R}$ and $\mathrm{CC}+\mathrm{R}$ were significantly smaller than those of the rice control. However, their homogenised counterparts did not show significant reduction in any of the glycaemic characteristics compared with the rice control.

\section{Eating rates}

The eating rates of $\mathrm{CC}+\mathrm{R}$ and $\mathrm{CE}+\mathrm{R}$ were significantly lower than those of pure rice and rice mixed with homogenised vegetables (Table 4). The eating rates of the meals showed a significant positive correlation with postprandial glycaemic characteristics, including $\mathrm{iAUC}_{0-120}$ values, peak values and MAGE $_{240}$ values $(P<0 \cdot 01)$.

\section{In vitro starch digestibility}

The amounts of glucose released from rice-vegetable meals and rice alone increased rapidly over $20 \mathrm{~min}$ during in vitro digestion and reached plateaus at 60-90 min (Fig. 5). The percentages of in vitro starch hydrolysis of $\mathrm{CP}+\mathrm{R}, \mathrm{CC}+\mathrm{R}$ and $\mathrm{CE}+\mathrm{R}$ were significantly lower than the percentages of the white rice sample at $20 \mathrm{~min}$ and beyond. The in vitro starch hydrolysis percentages of $\mathrm{CE}+\mathrm{R}$ at 20,60 and $120 \mathrm{~min}(52 \cdot 5$, 58.3 and $62.2 \%)$ were significantly lower than the percentages of HRE $+\mathrm{R}(73.8 \%, P=0.008 ; 77.9 \%, P=0.006$ and $84.4 \%, P=0.011)$ and $\mathrm{HCE}+\mathrm{R}(67.2 \%, P=0.001 ; 72.6 \%$, $P=0.005$ and $77.0 \%, P=0.002)$ at the time points mentioned above.
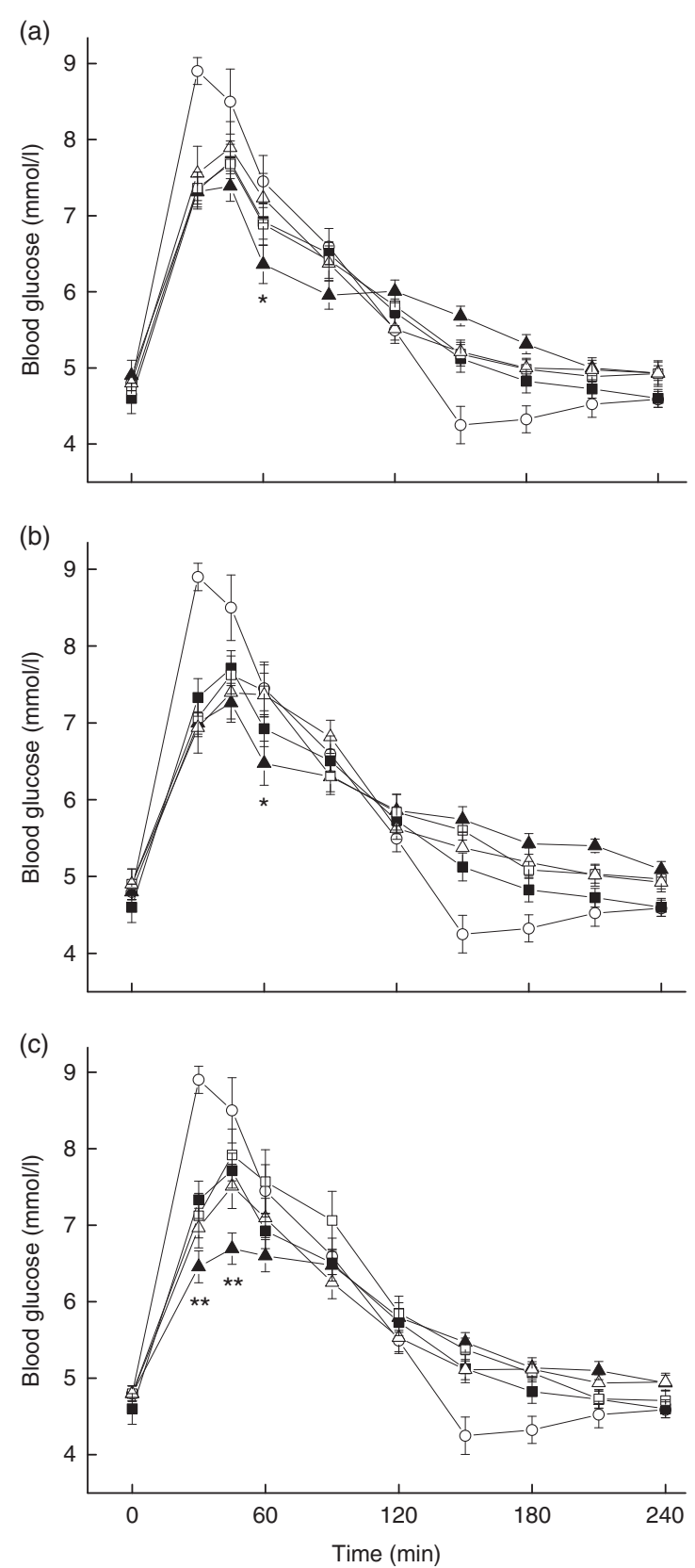

Fig. 4. Postprandial plasma glucose changes in subjects after the consumption of reference food and test meals, including (a) pak choi meals, (b) cauliflower meals and (c) eggplant meals, with glucose and rice as references (- - , glucose; - - - , cooked rice; - - - , cooked pak choi with cooked rice; - $\square$ homogenised raw pak choi with cooked rice; $-\Delta-$, homogenised cooked pak choi with cooked rice; - $\mathbf{\Delta}$ - cooked cauliflower with cooked rice; - - homogenised raw cauliflower with cooked rice; $-\triangle$ - , homogenised cooked cauliflower with cooked rice; - $\mathbf{\Delta}$, cooked eggplant with cooked rice; - $\square$, homogenised raw eggplant with cooked rice; $-\triangle-$, homogenised cooked eggplant with cooked rice). Values are the mean changes in blood glucose levels ( $n$ 16), with their standard errors represented by vertical bars. Differences between the cooked vegetable-rice mixed meal and two homogenised vegetables (cooked or raw) are shown $\left({ }^{\star} P<0.05,{ }^{\star \star} P<0.01\right)$.

Among all test meal samples, the HI value and RDS content of $\mathrm{CE}+\mathrm{R}$ were the lowest, whereas the $\mathrm{RS}$ fraction of $\mathrm{CE}+\mathrm{R}$ was the highest (Table 5). The addition of CC, CP, HRC and HRE increased the RS content, whereas the ingestion of HCC, HCP and HRP with rice caused an increase in SDS content. However, 
Table 5. Hydrolysis index and constituents of starch fractions of meal samples (Mean values and standard deviations)

\begin{tabular}{|c|c|c|c|c|c|c|c|c|}
\hline \multirow[b]{2}{*}{ Sample } & \multicolumn{2}{|c|}{$\operatorname{RDS}\left(\%^{\star}\right)$} & \multicolumn{2}{|c|}{$\operatorname{SDS}\left(\%^{\star}\right)$} & \multicolumn{2}{|c|}{ RS (\%*) } & \multicolumn{2}{|c|}{$\mathrm{HI}(\%)$} \\
\hline & Mean & SD & Mean & SD & Mean & SD & Mean & SD \\
\hline $\mathrm{R}$ & $35 \cdot 5^{\mathrm{a}}$ & 0.8 & $4 \cdot 9^{c}$ & 1.0 & $10 \cdot 2^{c}$ & 1.3 & 100 & - \\
\hline $\mathrm{CP}+\mathrm{R}$ & $34.9^{\mathrm{a}}$ & 2.0 & $4.5^{c}$ & 0.2 & $13 \cdot 4^{\mathrm{b}}$ & 1.7 & $83 \cdot 8^{b}$ & 1.7 \\
\hline $\mathrm{HRP}+\mathrm{R}$ & $35 \cdot 6^{\mathrm{a}}$ & 0.8 & $8 \cdot 4^{\mathrm{a}}$ & 1.8 & $8 \cdot 9^{c}$ & 1.2 & $91 \cdot 2^{\mathrm{a}}$ & 1.2 \\
\hline $\mathrm{HCP}+\mathrm{R}$ & $35 \cdot 8^{a}$ & 0.4 & $9 \cdot 6^{\mathrm{a}}$ & 0.5 & $7 \cdot 6^{d}$ & 0.8 & $92 \cdot 5^{\mathrm{a}}$ & 1.7 \\
\hline $\mathrm{CC}+\mathrm{R}$ & $35 \cdot 2^{a}$ & $2 \cdot 2$ & $3 \cdot 6^{\mathrm{c}, \mathrm{d}}$ & 0.1 & $16 \cdot 5^{a, b}$ & 1.8 & $80 \cdot 6^{b}$ & 1.0 \\
\hline $\mathrm{HRC}+\mathrm{R}$ & $38 \cdot 2^{a}$ & $4 \cdot 1$ & $2 \cdot 9^{d}$ & 0.2 & $14 \cdot 1^{\mathrm{b}}$ & 1.1 & $85 \cdot 5^{a, b}$ & 0.8 \\
\hline $\mathrm{HCC}+\mathrm{R}$ & $37 \cdot 1^{a}$ & 2.4 & $6.9^{\mathrm{b}}$ & 0.5 & $11 \cdot 3^{\mathrm{b}, \mathrm{c}}$ & $1 \cdot 1$ & $87 \cdot 2^{\mathrm{a}, \mathrm{b}}$ & 0.9 \\
\hline$C E+R$ & $28 \cdot 7^{\mathrm{b}}$ & $1 \cdot 1$ & $5 \cdot 3^{\mathrm{b}, \mathrm{c}}$ & 0.3 & $20 \cdot 7^{\mathrm{a}}$ & $1 \cdot 1$ & $69 \cdot 6^{c}$ & 0.3 \\
\hline $\mathrm{HRE}+\mathrm{R}$ & $36 \cdot 6^{\mathrm{a}}$ & 1.9 & $5 \cdot 3^{\mathrm{b}, \mathrm{c}}$ & 0.1 & $12 \cdot 9^{\mathrm{b}}$ & 1.0 & $86 \cdot 8^{\mathrm{a}, \mathrm{b}}$ & $2 \cdot 1$ \\
\hline $\mathrm{HCE}+\mathrm{R}$ & $38 \cdot 1^{a}$ & 2.4 & $5 \cdot 8^{\mathrm{b}, \mathrm{c}}$ & 0.1 & $8 \cdot 8^{\mathrm{c}}$ & 0.4 & $94 \cdot 6^{\mathrm{a}}$ & 0.9 \\
\hline
\end{tabular}

RDS, rapidly digestible starch; SDS, slowly digestible starch; RS, resistant starch; $H$, hydrolysis index; $R$, cooked rice; $C P+R$, cooked pak choi with cooked rice; HRP + R, homogenised raw pak choi with cooked rice; $\mathrm{HCP}+\mathrm{R}$, homogenised cooked pak choi with cooked rice; $\mathrm{CC}+\mathrm{R}$, cooked cauliflower with cooked rice; $\mathrm{HRC}+\mathrm{R}$, homogenised raw cauliflower with cooked rice; $\mathrm{HCC}+\mathrm{R}$, homogenised cooked cauliflower with cooked rice; $\mathrm{CE}+\mathrm{R}$, cooked eggplant with cooked rice; HRE $+\mathrm{R}$, homogenised raw eggplant with cooked rice; $\mathrm{HCE}+\mathrm{R}$, homogenised cooked eggplant with cooked rice.

a,b,c,d Mean values within a column with unlike superscript letters were significantly different $(P<0.05)$.

* The percentage of RDS, SDS or RS belonging to total starch.

\section{Discussion}

A number of previous studies reported that adding vegetables to a high-GI meal could exert a glycaemic mitigation effect $^{(16,17,23,33)}$, but, to our knowledge, the present study is the first study to compare the postprandial GR of non-homogenised and homogenised vegetables added to rice-based meals.

In this study, both the in vivo postprandial blood glucose tests and the in vitro carbohydrate digestion assays demonstrated that, compared with their homogenised counterparts, non-homogenised low-fat cooked vegetables could contribute more effectively to slow the carbohydrate digestion process or mitigate the postprandial GR. Co-ingestion of three servings ( $300 \mathrm{~g}$ of vegetable) of non-homogenised low-fat cooked pak choi, cauliflower and eggplant significantly lowered the GI values of rice-based meals, whereas the homogenised vegetables failed to achieve significant reduction in GI values. The outcomes of in vitro carbohydrate digestibility of vegetable-rice mixed meals echoed the results of the human blood glucose tests. These results strongly support our research hypothesis that is, the natural texture of vegetables might play an important role in GR and starch hydrolysis, as the homogenised vegetables, either cooked or uncooked, failed to render comparable glycaemic effects to their non-homogenised cooked counterparts in the first hour after the meal.

Some previous studies reported that both vegetables and vegetable juice might have simultaneous positive effects on GR and insulinaemic responses ${ }^{(16,33)}$. It was reported that a meal with $164 \mathrm{~g}$ of spinach elicited significantly lower insulin and C-peptide responses than the control meal $\operatorname{did}^{(13)}$. Compared with a meal consisting of $200 \mathrm{~g}$ of boiled rice, a mixed meal consisting of $200 \mathrm{~g}$ of rice and $120 \mathrm{~g}$ of Chinese cabbage had a 14.6\% lower incremental area above the blood insulin curve over $120 \mathrm{~min}^{(14)}$. In light of these results, the blood-glucosesuppressing effect of vegetables could not be attributed to raising insulin level, although the plasma insulin was not measured in the present study. The mechanism of glycaemic attenuation of vegetables might partly be explained by their slow ingestion, the dietary fibre's delaying effect on gastric emptying $^{(18,19)}$ and the polyphenol's carbohydrate digestion ${ }^{(34)}$.

It is noteworthy that the meals added with non-homogenised vegetable had significantly lower ingestion rates compared with their homogenised counterparts. Low eating rates might increase the level of anorexigenic gut peptide glucagon-like peptide 1 and peptide YY, and these peptide hormones have an important role to play in enhancing the glucose-stimulated insulin secretion ${ }^{(35-37)}$. It was reported that eating slowly and more chewing were associated with reduced GR and HbA1c and lower risk of diabetes ${ }^{(38)}$. In contrast, eating fast might be associated with insulin resistance in middle-aged individuals ${ }^{(39)}$.

The contribution of dietary fibre on glycaemic control has been well established. Soluble fibre such as pectin may absorb water, swell, become viscous and then establish a physical barrier between foods and digestion enzymes ${ }^{(40)}$. It is reported that pectin could delay gastric emptying of both liquid and solid meals by increasing the viscosity of the meals in normal human subjects while not causing significant variations in plasma insulin levels in healthy subjects ${ }^{(41)}$. In an animal study, pectin extracted from citrus improved glucose tolerance through regulation of the phosphoinositide 3-kinase/protein kinase $\mathrm{B}$ (PI3K/Akt) signalling pathway ${ }^{(42)}$. Soluble dietary fibre could be fermented to generate SCFA, which would up-regulate GLUT- 4 and attenuate the postprandial GR ${ }^{(43)}$.

However, the vegetable's texture itself could be an important factor to affect GR. Compared with liquid and semisolid foods, solid foods may have longer gastric emptying times ${ }^{(44,45)}$, which in turn delay the absorption of glucose into blood ${ }^{(23)}$. There is a randomised trial which proved that the physicochemical properties of dietary fibre influenced fibre's capacity for reducing appetite and energy intake when added to a diet as preload, because gelled pectin was more effective compared with the liquid pectin solution, though both the gelled and viscous liquid pectin lowered insulin responses ${ }^{(46)}$.

With the popularity of high-performance blenders in the modern kitchen, homogenised and juiced vegetables (semisolid or liquid) are often consumed instead of traditionally prepared 
vegetable dishes in many families, especially among young people who are less likely to cook at home. It should be noted that, with respect to their glycaemic benefits, homogenised vegetables may not be as effective as vegetable dishes in which the natural structure is well preserved.

In addition to the effect of fibre, the polyphenols in vegetables have the potential to inhibit the activity of carbohydrate digestion enzymes, such as $\alpha$-amylase and $\alpha$-glucosidase ${ }^{(47)}$. In an in vitro study, polyphenols from eggplant strongly inhibited $\alpha$-amylase and $\alpha$-glucosidase activities and thus provided a strong biochemical basis for management of hyperglycaemia-induced pathogenesis ${ }^{(48)}$. There is evidence that the absorbed polyphenols might up-regulate GLUT- 4 in skeletal muscle, PI3K in muscle and adipocytes and AMPactivated protein kinase in muscle, adipocytes, pancreas and liver, which would help to improve glucose homoeostasis ${ }^{(34)}$.

In this study, the steaming treatment of $\mathrm{CE}$ could maximise the phenolic retention, whereas the boiling treatment of CC and $\mathrm{CP}$ minimises the loss of polyphenols by the addition of a small amount of water and serving with the remaining water. In an animal study, it was also reported that the polyphenol content, the intestinal $\alpha$-glucosidase inhibitory activity and the antiglycation potential of green Amaranthus leafy juice were either enhanced or unchanged after cooking ${ }^{(21)}$

The timing of ingestion of vegetables might make a difference in terms of glycaemic effect. A study found that co-ingestion of $75 \mathrm{~g}$ of spinach with fat-rich and starch-rich meals failed to achieve a lowered GR in both healthy and obese subjects ${ }^{(32)}$, whereas another study reported that as little as $60 \mathrm{~g}$ of spinach or broccoli significantly lowered the iAUC of GR when taken as a side dish before the ingestion of starchy food ${ }^{(49)}$. In this study, one serving of the vegetable was given before the ingestion of rice, as the effects of eating vegetables before carbohydrate foods on glucose excursions was elaborated by Imai et $a l^{(15)}$.

It is noticed that the $\mathrm{CE}+\mathrm{R}$ meal had the lowest GI, peak and MAGE values among all GR test meals, and had the highest RS and lowest RDS in the in vitro digestion tests. Starchy foods of low RDS and high RS tend to result in relatively low postprandial $\mathrm{GR}^{(50)}$, and have the potential to enhance insulin sensitivity. Not coincidently, eggplant had the highest total polyphenol and total flavonoid contents, and the highest fibre content among the three vegetables. As eggplant is rich in polyphenols ${ }^{(51)}$ and fibre, it has been recommended by the National Diabetes Education Program of National Institute of Health, Mayo Clinic and American Diabetes Association for management of type 2 diabetes ${ }^{(52)}$.

However, given the fact that both the polyphenol and dietary fibre did not have any substantial loss after homogenisation, the difference of glycaemic effect among the three test samples of a same vegetable could only be explained by the divergence in physical structure. In light of this result, it is suggested that the strong GR mitigating effect of vegetables depends on the natural physical structure. The underlying mechanism requires further investigation.

This study has several limitations. First, the human subjects were healthy young Asian women of normal BMI and body fat percentages. Males, overweight and obese people and people with impaired blood glucose tolerance were excluded to avoid the confounders brought by differences in sex or metabolic status. The blood glucose modulation effect of vegetables may be more positive in abdominal obese people and prediabetic people, and thus deserve further investigation. Second, the gastric emptying rates, insulinaemic responses and gastrointestinal hormones were not determined in this study, although they would provide a more convincing explanation of glycaemic control mechanisms of the vegetable-rice mixed diet. Third, we only examined the effect of large amounts $(300 \mathrm{~g})$ of non-homogenised and homogenised vegetable on GR and starch digestion, and the effect of small amounts of vegetable was not evaluated. As mentioned above, the impact of small amounts remained controversial. Finally, although we analysed the polyphenols and dietary fibre, the biological active compounds such as solanine in eggplant and glucosinolates in cauliflower and pak choi, which might exert a positive role in GR, were not tested.

In conclusion, we found that both in vitro and in vivo tests supported the hypothesis that the texture/physical properties of vegetables might be a determinant of vegetables' postprandial glycaemic effects, whereas multiple factors including the eating rate, polyphenol content and dietary fibre content may play important roles in the underlying glycaemic control mechanisms as well.

\section{Acknowledgements}

The authors express their sincere gratitude to all the subjects who participated in the blood test study.

This research received no specific grant from any funding agency, commercial or not-for-profit sectors.

This description will cover the contribution of each author to the research. Z. F. and R. Z. formulated the research question, designed the study and wrote the article; R. Z., M. L., Y. H., L. W., T. Y. and J. L. carried out the experiments. R. Z. analysed the data.

The authors declare that there are no conflicts of interest.

\section{References}

1. Yang $\mathrm{CH}$, Chang $\mathrm{CW} \&$ Lin J (2017) White rice glycemic index measured in venous and capillary blood samples. Food Sci Technol Res 23, 297-304.

2. Boers HM, ten Hoorn JS \& Mela DJ (2015) A systematic review of the influence of rice characteristics and processing methods on postprandial glycaemic and insulinaemic responses. $\mathrm{Br} \mathrm{J}$ Nutr 114, 1035-1045.

3. Robert SD, Ismail AAS \& Rosli WIW (2016) Reduction of postprandial blood glucose in healthy subjects by buns and flatbreads incorporated with fenugreek seed powder. Eur $J$ Nutr 55, 2275-2280.

4. Kolb H \& Eizirik DL (2011) Resistance to type 2 diabetes mellitus:a matter of hormesis? Nat Rev Endocrinol 8, 183-192.

5. Guariguata L, Whiting DR, Hambleton I, et al. (2014) Global estimates of diabetes prevalence for 2013 and projections for 2035. Diabetes Res Clin Pract 103, 137-149.

6. Tuomilehto J, Lindstrom J, Eriksson JG, et al. (2001) Prevention of type 2 diabetes mellitus by changes in lifestyle among subjects with impaired glucose tolerance. $N$ Engl J Med $\mathbf{3 4 4}$, $1343-1350$ 
7. Ceriello A \& Colagiuri S (2010) International Diabetes Federation guideline for management of postmeal glucose: a review of recommendations. Diabetic Med 25, 1151-1156.

8. Cooper AJM, Sharp SJ, Luben RN, et al. (2015) The association between a biomarker score for fruit and vegetable intake and incident type 2 diabetes: the EPIC-Norfolk study. Eur J Clin Nutr 69, 449-454.

9. Mamluk L, O'Doherty MG, Orfanos P, et al. (2017) Fruit and vegetable intake and risk of incident of type 2 diabetes: results from the Consortium on Health and Ageing Network of Cohorts in Europe and the United States (CHANCES). Eur J Clin Nutr 71, 82-91.

10. Wu Y, Zhang D, Jiang X, et al. (2015) Fruit and vegetable consumption and risk of type 2 diabetes mellitus: a doseresponse meta-analysis of prospective cohort studies. Nutr Metab Cardiovasc Dis 25, 140-147.

11. Jia X, Zhong L, Song Y, et al. (2016) Consumption of citrus and cruciferous vegetables with incident type 2 diabetes mellitus based on a meta-analysis of prospective study. Prim Care Diabetes 10, 272-280.

12. Wolever TMS, Jenkins A, Vuksan V, et al. (1988) Effect of extra vegetables added to a starchy meal on blood-glucose responses in patients with type-2 diabetes. Can J Diet Assoc 49, 168-171.

13. Gustafsson K, Asp NG, Hagander B, et al. (1993) Effects of different vegetables in mixed meals on glucose homeostasis and satiety. Eur J Clin Nutr 47, 192-200.

14. Sun L, Ranawana DV, Leow MK, et al. (2014) Effect of chicken, fat and vegetable on glycaemia and insulinaemia to a white rice-based meal in healthy adults. Eur J Nutr $\mathbf{5 3}$ 1719-1726.

15. Imai S, Matsuda M, Hasegawa G, et al. (2011) A simple meal plan of 'eating vegetables before carbohydrate' was more effective for achieving glycemic control than an exchangebased meal plan in Japanese patients with type 2 diabetes. Asia Pac J Clin Nutr 20, 161-168.

16. Kasuya N, Okuyama M, Yoshida K, et al. (2016) Prior or concomitant drinking of vegetable juice with a meal attenuates postprandial blood glucose elevation in healthy young adults. Food Nutr Sci 7, 797-806.

17. Tiwari AK, Jyothi AL, Tejeswini VB, et al. (2013) Mitigation of starch and glucose-induced postprandial glycemic excursion in rats by antioxidant-rich green-leafy vegetables' juice. Pharmacogn Mag 9, S66-S73.

18. Yu K, Ke MY, Li WH, et al. (2014) The impact of soluble dietary fibre on gastric emptying, postprandial blood glucose and insulin in patients with type 2 diabetes. Asia Pac J Clin Nutr 23, 210-218.

19. Gopirajah R, Raichurkar KP, Wadhwa R, et al. (2016) The glycemic response to fibre rich foods and their relationship with gastric emptying and motor functions: an MRI study. Food Funct 7, 3964-3972.

20. Argyri K, Sotiropoulos A, Psarou E, et al. (2013) Dessert formulation using sucralose and dextrin affects favorably postprandial response to glucose, insulin, and c-peptide in type 2 diabetic patients. Rev Diabet Stud 10, 39-48.

21. Kumar DA, Anusha SV, Oruganti S, et al. (2015) Raw versus cooked vegetable juice. Nutr Foods 14, 27-38.

22. Samra RA \& Anderson GH (2007) Insoluble cereal fiber reduces appetite and short-term food intake and glycemic response to food consumed 75 min later by healthy men. $A m J$ Clin Nutr 86, 972-979.

23. Ballance S, Knutsen SH, Fosvold OW, et al. (2018) Glyceamic and insulinaemic response to mashed potato alone, or with broccoli, broccoli fibre or cellulose in healthy adults. Eur $J$ Nutr 57, 199-207.
24. Ek KL, Wang S, Copeland L, et al. (2014) Discovery of a lowglycaemic index potato and relationship with starch digestion in vitro. Br J Nutr 111, 699-705.

25. European Union (2011) Regulation no. 1169/2011 of the European Parliament and of the Council on the provision of food information to consumers. Off J Eur Union 304, 18-63.

26. Singleton VL, Orthofer R \& Lamuela-Raventós RM (1999) Analysis of total phenols and other oxidation substrates and antioxidants by means of Folin-Ciocalteu reagent. Methods Enzymol 299, 152-178.

27. Xu BJ, Yuan SH \& Chang SK (2007) Comparative analyses of phenolic composition, antioxidant capacity, and color of cool season legumes and other selected food legumes. J Food Sci 72, 167-177.

28. Broadhurst RB \& Jones WT (1978) Analysis of condensed tannins using acidified vanillin. J Sci Food Agric 29, 788-794.

29. Englyst HN, Veenstra J \& Hudson GJ (1996) Measurement of rapidly available glucose (RAG) in plant foods: a potential in vitro predictor of the glycaemic response. $\mathrm{Br} J$ Nutr $\mathbf{7 5}$, 327-337.

30. Englyst KN, Englyst HN, Hudson GJ, et al. (1999) Rapidly available glucose in foods: an in vitro measurement that reflects the glycemic response. Am J Clin Nutr 69, 448-454.

31. Brandmiller JC, Stockmann K, Atkinson F, et al. (2009) Glycemic index, postprandial glycemia, and the shape of the curve in healthy subjects: analysis of a database of more than 1000 foods. Am J Clin Nutr 89, 97-105.

32. Wolever TMS (2004) Effect of blood sampling schedule and method of calculating the area under the curve on validity and precision of glycemic index values. BrJ Nutr 91, 295-300.

33. Gustafsson K, Asp NG, Hagander B, et al. (1993) Effects of different vegetables in mixed meals on glucose homeostasis and satiety. Eur J Clin Nutr 47, 192-200.

34. Kim Y, Keogh JB \& Clifton PM (2016) Polyphenols and glycemic control. Nutrients $\mathbf{8}, 17$.

35. Kokkinos A, Le RC, Alexiadou K, et al. (2009) The postprandial response of the anorexigenic gut hormones PYY and GLP-1 is affected by eating rate. Diabetologia 52, S227.

36. Sonoki K, Iwase M, Takata Y, et al. (2013) Effects of thirty-times chewing per bite on secretion of glucagon-like peptide- 1 in healthy volunteers and type 2 diabetic patients. Endocr J 60 , 311-319

37. Kokkinos A, Roux CWL, Alexiadou K, et al. (2010) Eating slowly increases the postprandial response of the anorexigenic gut hormones, peptide YY and glucagon-like peptide-1. J Clin Endocrinol Metab 95, 333-337.

38. Yamazaki T, Yamori M, Asai K, et al. (2013) Mastication and risk for diabetes in a Japanese population: a crosssectional study. PLOS ONE 8, e64113.

39. Otsuka R, Tamakoshi K, Yatsuya H, et al. (2008) Eating fast leads to insulin resistance: findings in middle-aged Japanese men and women. Prev Med 46, 154-159.

40. Cassidy YM, McSorley EM \& Allsopp PJ (2018) Effect of soluble dietary fibre on postprandial blood glucose response and its potential as a functional food ingredient. J Funct Foods 46, 423-439.

41. Sandhu KS, Samahi MME, Mena I, et al. (1987) Effect of pectin on gastric emptying and gastroduodenal motility in normal subjects. Gastroenterology 92, 486-492.

42. Liu Y, Dong M, Yang Z, et al. (2016) Anti-diabetic effect of citrus pectin in diabetic rats and potential mechanism via PI3K/Akt signaling pathway. Int J Biol Macromol 89, 484-488.

43. Galisteo M, Morón R, Rivera L, et al. (2010) Plantago ovata husks-supplemented diet ameliorates metabolic alterations in obese Zucker rats through activation of AMP-activated protein 
kinase: comparative study with other dietary fibers. Clin Nutr 29, 261-267.

44. Okabe T, Terashima H \& Sakamoto A (2017) A comparison of gastric emptying of soluble solid meals and clear fluids matched for volume and energy content: a pilot crossover study. Anaesthesia 72, 1344-1350.

45. Gonlachanvit S, Chey WD, Goodman KJ, et al. (2001) Effect of meal size and test duration on gastric emptying and gastric myoelectrical activity as determined with simultaneous ${ }^{13} \mathrm{C}$ octanoate breath test and electrogastrography in normal subjects using a muffin meal. Digest Dis Sci 46, 2643-2650.

46. Wanders AJ, Feskens EJM, Jonathan MC, et al. (2014) Pectin is not pectin: a randomized trial on the effect of different physicochemical properties of dietary fiber on appetite and energy intake. Physiol Behav 128, 212-219.

47. Tan Y \& Chang SKC (2017) Digestive enzyme inhibition activity of the phenolic substances in selected fruits, vegetables and tea as compared to black legumes. J Funct Foods 38, 644-655.
48. Kwon YI, Apostolidis E \& Shetty K (2008) In vitro studies of eggplant (Solanum melongena) phenolics as inhibitors of key enzymes relevant for type 2 diabetes and hypertension. Bioresour Technol 99, 2981-2988.

49. Kameyama N, Maruyama C, Matsui S, et al. (2014) Effects of consumption of main and side dishes with white rice on postprandial glucose, insulin, glucose-dependent insulinotropic polypeptide and glucagon-like peptide- 1 responses in healthy Japanese men. Br J Nutr 111, 1632-1640.

50. Kuma A, Sahoo U, Baisakha B, et al. (2018) Resistant starch could be decisive in determining the glycemic index of rice cultivars. J Cereal Sci 79, 348-353.

51. Niño-Medinaa G, Urías-Oronab V, Muy-Rangelc MD, et al. (2017) Structure and content of phenolics in eggplant (Solanum melongena): a review. S Afr J Bot 111, 161-169.

52. National Institutes of Health (NIH) (2008) National Diabetes Education Program. http://www.ndep.nih.gov/diabetes/ Mealplanner/enlasagna.htm (accessed May 2007). 